\title{
Frontier Literature Review of Social Entrepreneurship Based on Knowledge Map
}

\author{
Hewu Chen \\ College of Business,Shanghai University of Finance\& Economics,Shanghai,China \\ chenhewu@yeah.net
}

Keywords: Social entrepreneurship (SE), knowledge map, literature review, Citespace

\begin{abstract}
Social entrepreneurship (SE) is the frontier areas of strategic management and entrepreneurial management research, which is still in its infancy. This paper uses Citespace software to do the knowledge map analysis in terms of time distribution, spatial distribution, periodical distribution and author distribution to all the SE research literatures, which are collected from 19 kinds of international top management and entrepreneurial academic journals in the Web of Science database. It also analyzes deeply the hot topics of in the field of SE. The study results show that SE research is increasing rapidly at present. The connotation and characteristics of SE and social entrepreneurs, process, influencing factors and performance evaluation are the three major hotspots of the SE research. Research in the future should focus on the ways in which social enterprises can gain competitive advantage from "outside" to "inside" from research perspective. Meanwhile, the research method should be changed from "narrow" to "broad" and we should pay more attention to the empirical research of multidisciplinary, cross-circumstance of multi-case and big data samples, which may promote empirical research deeply. What's more, more emphasis should be placed on the uniqueness of SE and local context research, which contributes to the research content from "shallow" to "deep".
\end{abstract}

\section{Introduction}

Since traditional charitable relief and government support cannot fundamentally solve a large number of new social problems, social entrepreneurship (SE) has become a possible way to deal with market failures, government failures and voluntary failures. As an emerging innovative entrepreneurial approach to solving complex social problems(Johnson,2000), SE is not only the theoretical focus of academic attention, but also an effective policy tool to respond to the needs of people in the new era for a better life. This wonderful life is not only at the economic level, but also reflected in people's new expectations in many aspects of education, medical care, employment, pension, and ecological environment. In recent years, SE has received an increasing attention at home and abroad, as an independent research field (Dacin el al., 2011), which solves specific social problems and obtains certain business income (Dees, 2003; Austin, 2006; Zahra, 2016; Hockerts, 
2017). To sum up, the rise of SE has the following factors:

First of all, SE is an effective supplement to solve the "triple failure" of society. Compared with economic development, social and environmental issues are deteriorating, and sustainable and inclusive development has become an important global issue. As social values become more and more important, and the emergence of the "triple failure" of the government, the market and the volunteers, SE represented by social enterprises has quietly emerged, and the transformation from technological innovation to social innovation has become an inevitable trend. Because of the "double bottom line” of social value and economic value (Alter, 2000), SE aims to provide innovative solutions to unresolved social problems, and to make social value creation the core of its mission to improve their lives and well-being about individuals and communities.

Second, the expansion of the corporate social responsibility movement and the dilemma of the development of non-profit organizations. Under the corporate social responsibility movement continues to expand, more and more enterprises are paying more attention to social values and environmental values while pursuing economic value. At the same time, since income sources rely more on donations or government-funded "transfusion" rather than "hematopoietic" financial constraints (Defourny and Nyssens,2010), the traditional non-profit organization's mode of operation is difficult to adapt to the new background of SE, many non-profit organizations began to use commercial operation mode to transform into social enterprises(Salamon,2014),and venture capital or social influence investment became the accelerator of non-profit organization transformation, which is an emerging financing tool and capital form for market-solving social problems.

Third, innovation, entrepreneurship, strategic management, non-profit organizations, and social innovation are the frontiers of research. At present, the boundary between business and public welfare has gradually become blurred, and there is a great limitation in studying a social problem from a single discipline. From the development trend of modern scientific theory, cross-integration is in line with the development trend of social science (Goodall and Oswald, 2014). Entrepreneurship management, as one of the fastest growing research fields in recent years, is a new research paradigm that has formed an independent disciplinary system (Shane, 2000).SE research is one of the core areas, and its integration with strategic management, non-profit organizations, and social innovation will be the frontier of research. However, SE research lacks an unified paradigm and its boundary is vague compared to other research fields. In recent years, scholars who have studied SE from the perspectives of sociology, public administration, management and psychology begun to increase, but they have not yet formed a systematic theoretical research framework and system, which is likely to cause confusion.

The rest of the paper is organized as follows: Section 2 explains the data sources and research methods. Section 3 analyzes the distribution characteristics of the SE frontier literature. Section 4 elaborates the hot topics of SE research. Section 5 is the conclusion and research outlook.

\section{Data Sources and research Methods}

\subsection{Data Sources}

This paper uses the Science Citation Database Web of Science Core Collection (WOS) as the information source, and uses the combination method of "topic + publication name" to search for 19 frontier literatures of internationally influential management and entrepreneurship journals ${ }^{1}$. A total

\footnotetext{
${ }^{1} 19$ journals include the top 5 international management journals (AMJ, AMR, ASQ, SMJ, and Organization Science) and three major entrepreneurial journals (JBV, SEJ, ETP), and 11 other journals in management or entrepreneurship. Larger impact journals (JWB, ERD, IEMJ, ISBJ, JBE, JBR, JIBS, JMS, SBE, JSBM, and Organization Studies).
} 
of 260 records were retrieved. The specific search design and results are shown in Table 1.

Table 1 Search design and search results

\begin{tabular}{ll}
\hline $\begin{array}{l}\text { Retrieve design } \\
\text { subjects }\end{array}$ & Retrieve design content and results \\
\hline database & Web of ScienceTM Core Collection \\
\hline $\begin{array}{l}\text { Search method } \\
\text { TS ( social entrepreneurship }) \text { OR TS = (social venture(s) }) \text { OR TS } \\
\text { (social business })\end{array}$ \\
\hline Category & Management, Business, Economics, Ethics, Planning Development \\
\hline Document type & Article, Review,Editorial Material,Book Review,Proceedings paper \\
\hline Language & English \\
\hline time span & 2005-2017 \\
\hline $\begin{array}{l}\text { Data download } \\
\text { method }\end{array}$ & Fully documented and contains references cited \\
\hline Search time & January 15, 2018 \\
\hline Search Results & 260 \\
\hline
\end{tabular}

\subsection{Research methods}

As a visual knowledge mapping tool, Citespace can track the research status and hotspots of a certain subject by analyzing the literature in a specific field, which help to discover and display the development trend and the latest frontier of the subject. In the field of entrepreneurship management, the research fields currently using knowledge mapping tools include entrepreneurial research, international entrepreneurship, entrepreneurship failure, entrepreneurship education, etc., but there are few visual literatures on the evolution and hotspots of SE research. Therefore, based on CiteSpace4.0.R2 software, this paper analyzes the knowledge of SE research, and combines national and institutional analysis, author analysis, journal analysis, keyword analysis and other methods to master the key achievements and the development of the entire field of SE research.

\section{Distribution Characteristics of the Frontier Literature of SE}

\subsection{Annual distribution characteristics}

According to Figure 1, the evolution path of SE research can be roughly divided into three stages. Before 2006, it was the stage of germination. At this stage, there is less research literature on the field of SE. In 2005 alone, there were two sporadic research results of JBV. Between 2006 and 2009 is a period of steady growth, which SE research has begun to increase and it has gradually been recognized by the international academic community. Among them, 2006 is a very significant year for SE research, and the citation rate is high (such as Austin et al, 2006; Mair and Martí, 2006; Peredo and McLean, 2006; Weerawardena and Mort, 2006). However, this stage of literature research still focuses on the definition and connotation of SE concepts, feature analysis, and descriptive case studies. Based on a review of 152 articles, Short et al.,(2009)believed that SE research has just started, empirical research articles were far less than conceptual articles, and academic results in mainstream journals were still few. It is necessary to conduct multivariate quantitative research instead of past dominant. Case studies to promote the development of this field. Since 2010, it has been a period of rapid growth.SE research has continued to grow rapidly. In 2010, there were more than 26 publications and 56 publications in 2016. There have been academic papers related to SE in the 
international management and entrepreneurship journals. At this stage, the SE research began to gradually turn to the theoretical framework construction and empirical measurement analysis of SE(Tracey et al.,2011;Mair et al.,2012; Stevens et al.,2015; Mcmullen et al.,2017).

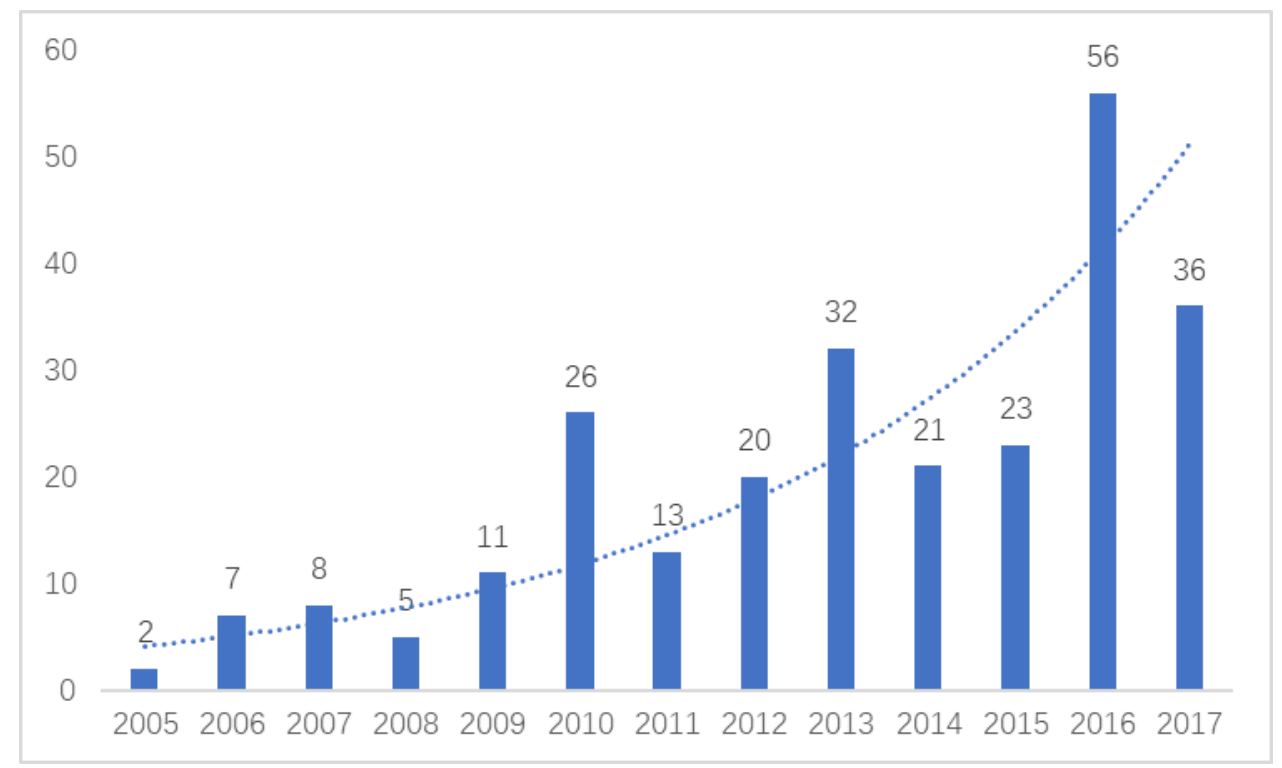

Fig. 1 Time distribution of literature in the field of SE

\subsection{Regional distribution characteristics}

According to Figure 2, SE research is mainly centered on the USA and UK. USA has an absolute advantage and ranks 1 , whose total number of articles issued is 109 and number of citations reached 103. In the entire network map, the USA has a centrality of 1.15 , the thickest connection with other countries, indicating that USA has the closest cooperation with many countries in the co-occurrence network, such as the UK, Canada, Spain, Australia, and so on. Among the top 15 organizations, Indiana University, Cambridge University, Oxford University, and Queensland University of Technology are the high-yield institutions for SE research literature. Among them, Indiana University ranked 1th in the world with 15 articles. Although UK is far worse than USA, it is significantly more than other countries, with 62 articles and 59 times, which ranked 2th.Organizations with a large number of documents included Cambridge, Oxford, University of Surrey, Imperial College London, Strathclyde, of which Cambridge ranked 1th in Europe and 2th in the world with 11 articles. In addition, countries with a large number of SE research publications included Canada, Spain, Australia, etc. Institutions of SE research literature included the University of Queensland, Massey University, University of Valencia, etc. It is worth noting that from the perspective of national centrality, Spain, Canada, Australia, Germany and France all exceeded 0.1, indicating that these countries have more cooperation in the field of SE research and have greater academic influence. From the perspective of institutional centrality, Oxford University alone exceeds 0.1,indicating that Oxford University and other universities have close cooperation in SE research, while Indiana University and Cambridge University have higher numbers of citations and citations. However, the centrality is low, indicating that they have less cooperation with other universities in the field of SE research. It can be seen that the United States and Europe, as countries with developed social enterprises, are also the first camp of SE research, leading the publication of the world's top journals on SE research. 


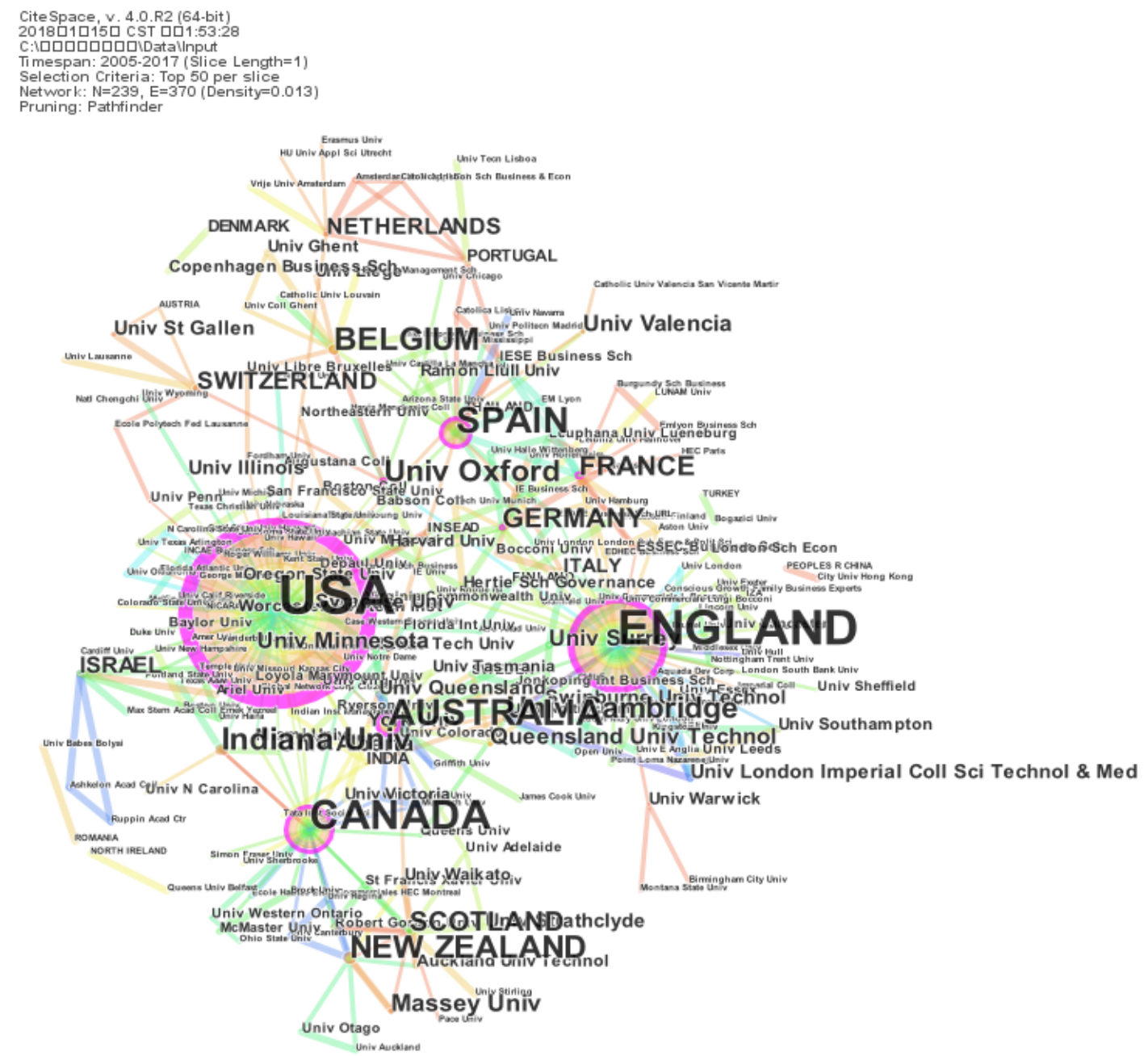

Fig. 2 Social network diagram of SE research countries and institutions

\subsection{Distribution characteristics of journals}

As shown in Figure 3, from the nodes (35), connections (129) and network density (0.2168) of the map, it can be seen that there are more connections between the journals, but the degree of network cohesion is low, indicating the journal of global SE research. The cooperation between the two is not too close. In terms of the number of articles published, JBE, ERD and ETP ranked in the top three, with 53, 33 and 32 respectively, leading the research in the field of SE. and reflecting research hotspots and frontier theme in the field in this field. In addition, Journals such as JBV, ISBJ, JMS also publish many representative research results in the field of SE. From the node point of view, the circle node of AMR is the largest, that is, the center is the largest (0.62), and the frequency of reference is also the highest, reaching 204 times, indicating that AMR is the absolute domain core, although the number of documents about SE is not much (5), but the quality of the article is very high and is cited the most. Followed by ETP, its centrality is 0.32 , and the frequency of citations reaches 187 , indicating the authoritative position of its SE research literature in the journal of entrepreneurship. In addition, the centrality of JBV, ISBJ, ERD, SMJ, AMJ exceeded 0.1, and the literature in the field of SE research has great influence. However, although ASQ, JMS, and Organizaiton Science have higher citation frequencies, their centrality is relatively low, indicating that their connection in the network of co-cited journals is still not strong and needs to be further improved. Therefore, to 
accurately grasp the cutting-edge research results in the field of SE, not only need to pay attention to the number of journals published, but also need to pay attention to the co-citation frequency and centrality of journals.

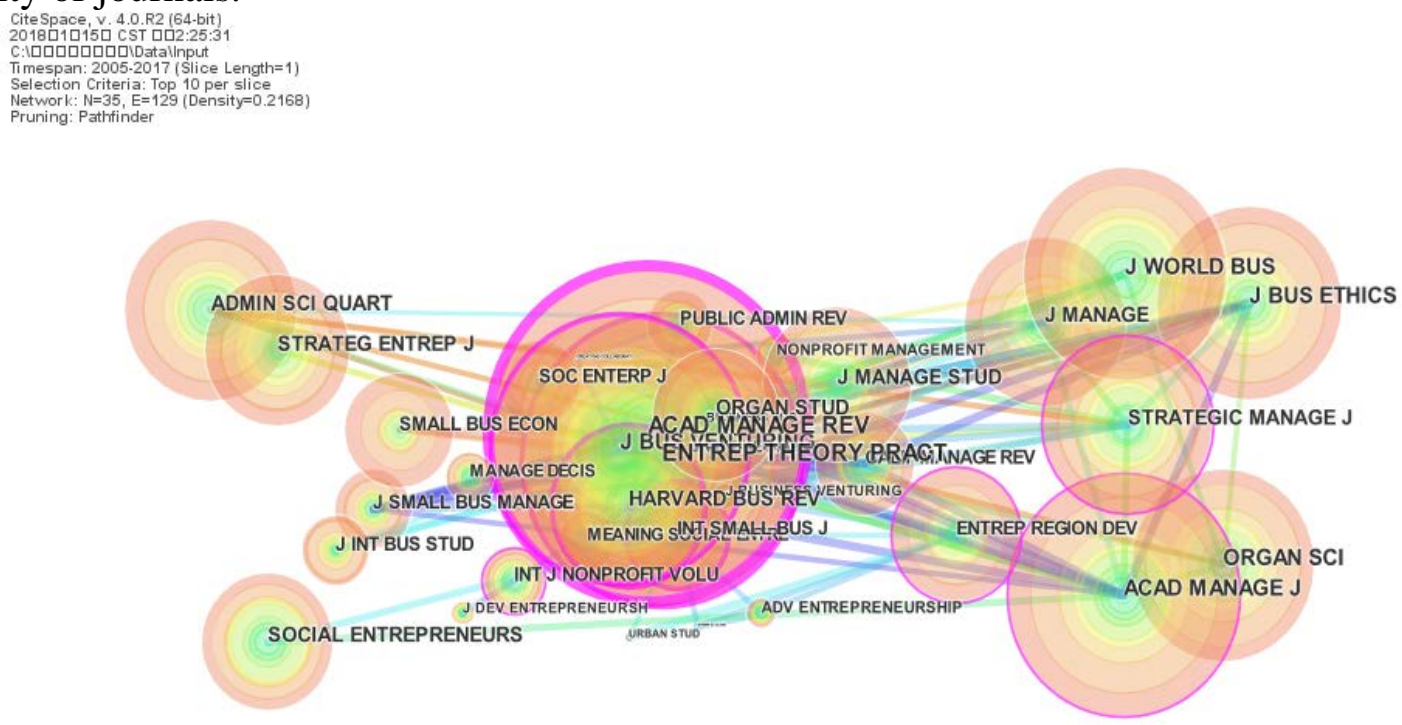

Fig. 3 SE research Co-introduced journal distribution network map

\subsection{Author distribution characteristics}

According to the centrality of the map(Figure 4), the authors' centrality is greater than 1 including Shane (University of Maryland), Mair (Hertin School of Management, Berlin), Austin (Harvard Business School), Dees (Duke University), Zahra (University of Minnesota), Peredo (University of Victoria), indicating that they have a strong academic influence in the field of SE research.From the author's citation frequency, Mair, Zahra, Austin are in the top three. The top five scholars in the field of SE research are Tracey (Cambridge University), Mcmullen (Indiana University), Mair, Nicholls (Oxford University), and Zahra. Paying attention to the research topics of the above representative authors helps us to understand the development frontier of SE theory in a timely manner. However, it is worth noting that although Tracey and Mcmullen posted 8 and 6 articles respectively, ranking first and second, they were lower in frequency and centrality in the map, and did not enter the top 10. Although Dees has a small amount of publications(only one), but the centrality is very high, reaching 0.27 , and the frequency of citations is also 67 . Shane has only a small number of articles cited in SE, only 63 times. However, the centrality has the highest score of 0.38.Mair's article has been cited the most frequently, reaching 146 times. It is the largest key node in the network, with 5 articles and a high center, reaching 0.37. It can be seen that the academic influence of Shane and Mair in the field of SEresearch is very large.Authors with a large number of papers,such as Tracey and Mcmullen, are not highly cited in the network map, and their academic influence has not been widely recognized. In addition, from the author's number of publications, there are not many high-yield authors who independently study in the field of SE research, and the authors and others have a high proportion of research, and the proportion of authors published by two or more authors is as high as $80 \%$. 


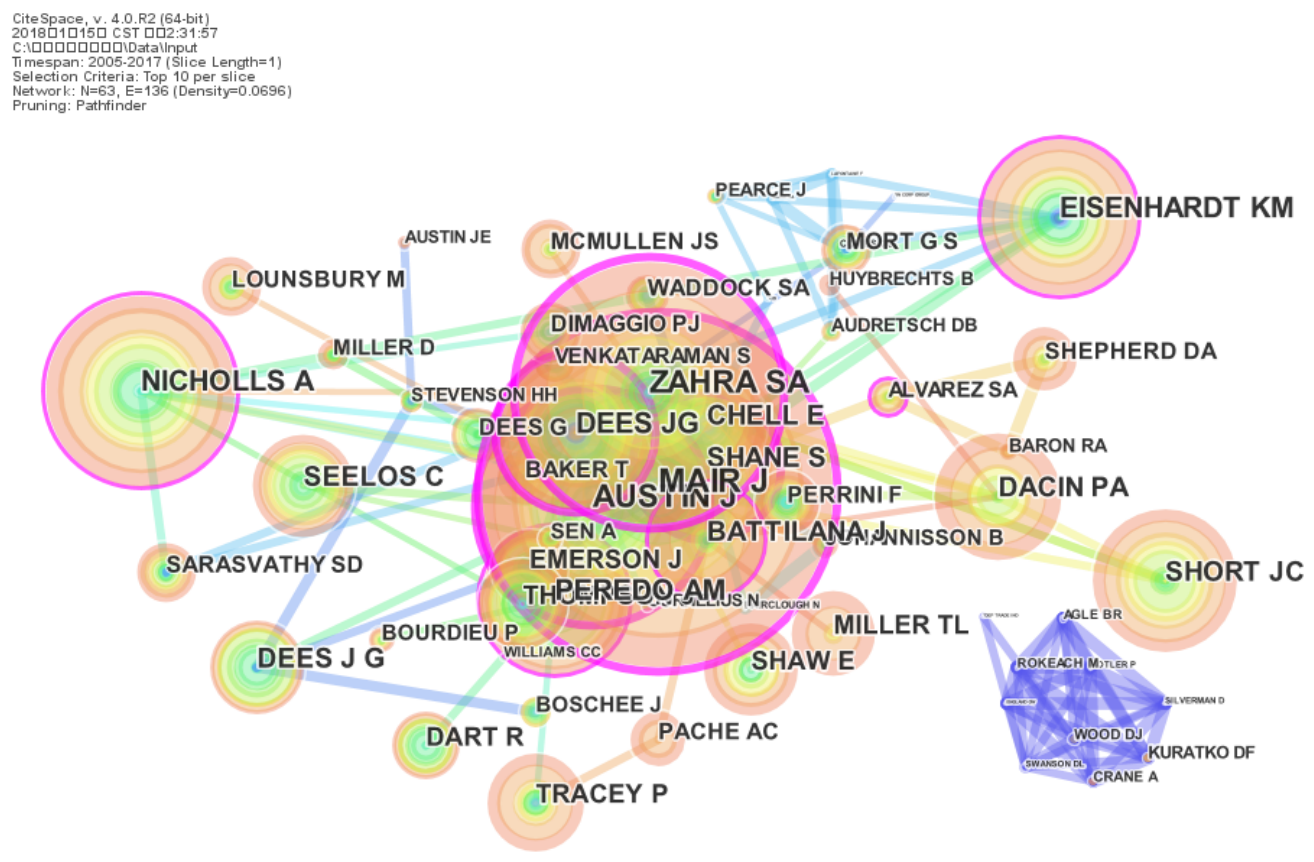

Fig. 4 SE research co-cited author distribution network map

\section{Analysis of Hotspots in SE Research}

As shown in Figure 5,SE research is generally loose and not high in density, and the accuracy and concentration of research topics need to be further strengthened. In the field of SE research, SE, entrepreneurship, performance, organizations, innovation, opportunities, enterprise, business, social enterprise, legitimacy, perspective, etc. are frequently appearing keywords. It is further combed that the hotspots of SW research in 2005-2017 mainly focus on three directions: the research perspective of SE connotation and characteristics; the research perspective of SE process; the impact factors of $\mathrm{SE}$ and the perspective of performance evaluation.

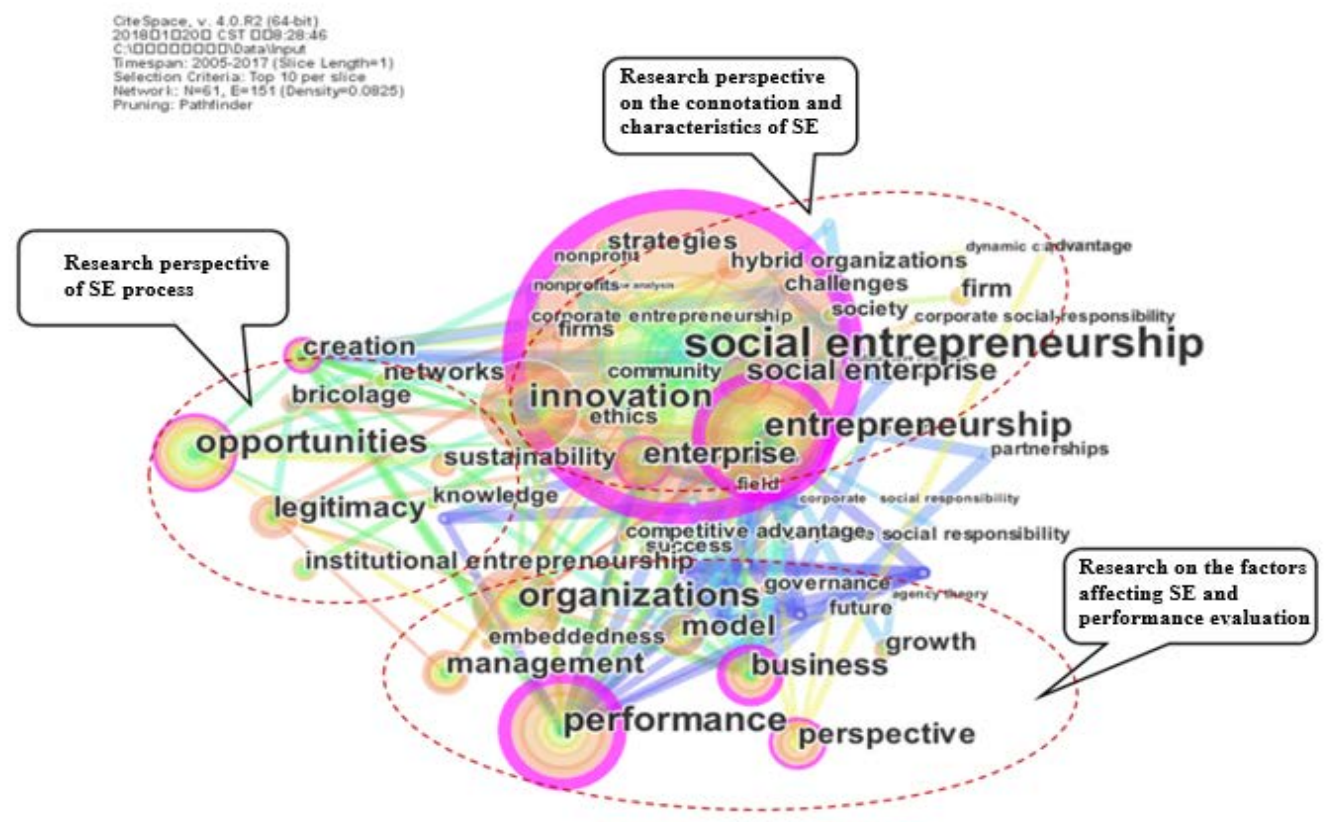

Fig. 5 Research hotspot network map of SE research 


\subsection{Research perspective on the connotation and characteristics of SE}

SE terms often overlap with terms such as the third sector, non-profit organizations, social economy, and social enterprises. At present, the academic community's views on the meaning of SE are not uniform. Austin et al., (2006) conducted a comparative analysis of SE and commercial entrepreneurship. The analysis of the four aspects of market failure, mission, resource mobilization and performance strategy emphasized the main similarities and differences between the two forms of entrepreneurship, and proposed how to be more systematic and effective. The framework for dealing with the SE process. Weerawardena and Mort (2006) used the Grounded Theory method to conduct in-depth case studies of nine non-profit organizations of social entrepreneurs, and built a multi-dimensional model of SE, which proposed the core of innovation, initiative and risk management. The behavioral dimension determines the constraints of environmental, social mission and sustainability on SE. Mair and Marti (2006) argued that SE differed from other forms of entrepreneurship because it insisted on promoting social values and development priorities rather than gaining economic value. Short et al., (2009) believed that SE used the practices and processes unique to entrepreneurship to achieve obvious social goals, regardless of whether they have profit motives. Zahra et al.,(2009) argued that SE refers to activities and processes for the discovery, protection and use of opportunities to enhance social wealth by creating new businesses or managing existing organizations in innovative ways (these social wealth includes the economy, social, health and environmental aspects).In general, as a practice of integrating economic and social value creation, $\mathrm{SE}$ is regarded as an entrepreneurial process based on social purposes and solving social problems through commercial means. The fundamental motivation is to create social value, not just the wealth of individuals or shareholders. Social enterprises represent a mix of traditional values associated with for-profit and non-profit activities within the same enterprise. At present, there are the following research consensuses on the connotation and characteristics of SE: first, public welfare, emphasis on solving social problems, social mission priority; secondly, market-oriented, gaining economic benefits through business models, but dividends to social enterprises There is still a lot of controversy in reality; the third is innovation, emphasizing innovative ways to address social issues.

Social entrepreneurs are actors who create social values by innovating industry practices that meet social needs (Austin et al., 2006; Zahra et al., 2009), they create services in the social sector by creating new organizations that serve a wide range of social needs. The role of change agents, thereby improving the quality of life and promoting human development around the world. Therefore, the mission of social entrepreneurs is not for personal value, but for creating social value. Social entrepreneurs refered to entrepreneurs who establish companies primarily to achieve social goals rather than create personal financial profits (Mair and Mart, 2006). Peredo and McLean (2007) argued that social entrepreneurs were people who described social goals and ran an organization or company in a way that created social value. Although there is no definitive way to determine the importance of social goals so that they cannot become the boundaries of social entrepreneurs, the main difference between social entrepreneurs and other forms of entrepreneurs is a commitment to provide social value. Based on the research work of Hayak, Kirzner and Schumpeter, Zahra et al., (2009) proposed three types of social entrepreneurs, namely Social Bricoleur, Social Constructionist and Social Engineer. There are differences in how to define opportunities, view their mission, access resources, and respond to social ills, and discuss the ethical issues that social entrepreneurs need to pay attention to. In summary, the existing literature has two main views on social entrepreneurs. The first one emphasizes "entrepreneurship" and believes that social entrepreneurs, like commercial entrepreneurs, are exploring opportunities and acquiring resources. Entrepreneurship in terms of innovative learning, but the concern of social entrepreneurs in terms of economic interests is significantly different from that of commercial entrepreneurs. This stems from the entrepreneurial 
heart and mission of social entrepreneurs(Mair and Mart,2006;Peredo and McLean,2006).The second view emphasizes "society" and believes that social entrepreneurs are the changers who promote the development of social enterprises, emphasizing responsibility and initiative for solving social problems, and paying more attention to social changes, but may be in society. There are differences in the ethics, legitimacy, and success rate of entrepreneurs (Renko, 2013; Parkinson and Howorth, 2008).

\subsection{Research perspective of SE process}

According to the knowledge map, opportunity identification, resource acquisition, and legitimacy are the focus of SE research.

\subsubsection{Opportunity identification of SE.}

Although opportunities of SE may intersect with opportunities in the business sector, they are different and need to be tested in their respective fields, and opportunities of SE are more than those of business entrepreneurship (Austin et al., 2006). The research on opportunity identification of SE mainly includes the same and difference between traditional business entrepreneurship opportunities and SE opportunities (Vanessa and Isabell, 2011; Katrea and Salipante, 2012; Lumpkin et al., 2013). How does opportunity identification play a central role in the process of SE(Mair and Mart,2006);Exploring and developing opportunities for SE(Zahra et al.,2009;Patricia and Marcus,2010);the opportunity attributes of global SE(Zahra et al.,2008); the impact of empathy and embedding agents on the process of SE opportunities(Grimes et al.,2013).For example, Zahra et al.,(2008) argued that global poverty gaps, corporate social responsibility movements, markets, institutions and government failures, technological advances and shared responsibilities are the four global forces driving SE globalization and describe global entrepreneurial opportunities. 5 standards. The diversity of these standards highlights the complexity of the social entrepreneurial decision-making process and helps explain the satisfaction behaviors noted in these decisions. Patricia and Marcus(2010) used an inductive, theoretically constructed case study approach to analyze how SE opportunities create and exploit social values. They believed that dynamics and complexity are typical features of opportunity identification processes of SE. Opportunity Development, Collective Action, Experience Corridors, and Spark Notion are the four main modes of SE identification. Lumpkin et al.,(2013) explained the extent to which the causes and effects of SE have a unique impact on the entrepreneurial process. The analysis showed that many SE processes remain essentially unchanged or are only marginally affected. However, autonomy, competitive enthusiasm and risk-taking are somewhat influenced by the presence of multiple stakeholders and the availability of resources or funds. The SE process may also differ when trying to meet multiple stakeholders and achieve sustainable solutions. Grimes et al.,(2013) combined the social entrepreneur's sympathy with the embedding agent and believe that the SE process is embedded in the institutional matrix, and the individual is actually the combination of motivation, cognition, and capital that constitutes the entrepreneurial organization involved in the process. One of the motivations is compassion, which has received great attention. However, although scholars have studied many questions about SE opportunities and tried to explain whether these opportunities were discovered or created, they are still not well answered.

\subsubsection{Resource acquisition of SE.}

The research on the resource acquisition of SE mainly includes how social enterprises acquire resources, the role of resource bricolage, the ways of social entrepreneurs obtain resources through 
social venture capital and social networks. For example, Domenico et al.,(2010) used the patchwork theory to show that the socially fragile process is related to the resource-poor environment which promoted social enterprises use all available means to access unused or underutilized resources that can be leveraged in different ways to create social value. Meyskens et al., (2010) empirically analyze the process of SE, based on the resource-based perspectives (RBV), and found that social entrepreneurs use the same process of internal operations as commercial entrepreneurs in the process of using resource bundles. Desa(2012) believed that the technical risks of identifying and acquiring resources in the field of entrepreneurship in the international community are explored, and that social enterprises strive to find a balance between social impact and financial viability. Contrary to the mainstream view of resource mobilization, social entrepreneurs facing institutional constraints have reformed their existing resources. In this process, vulnerability can be used as a legal mechanism for institutional change. Social enterprises mobilize resources through patchwork, which is conducive to their legalization and institutional support. Desa and Basu(2013) argued that the flow of resources from social enterprises is especially critical to the completion of social missions. They studied the optimization of two processes of resource mobilization, which called optimization and bricolage, and the preconditions for the two processes of social enterprise selection. They proposed an U-shaped relationship between resource adequacy and organizational reputation and patchwork behavior. Miller et al., (2012) believed that SE promoted the development of social venture capital, and this innovative source of funding changes the way social entrepreneurs obtain resources. Social enterprise creation is usually led by social catalysis and community, so community-based networks become a key resource, and larger social networks can provide social entrepreneurs with more access to resources and survival opportunities. It can be seen that resource patchwork and social networks are important ways to obtain SE resources.

\subsubsection{Legality of SE.}

The study of the legitimacy of SE mainly includes two aspects. First, it analyzes the legality of social enterprise organizational form from the perspective of macro-legality strategy, and seeks ways for the legitimacy of social enterprise organization. For example, Sud et al., (2009) argued that social enterprises represent a fundamental innovation in the non-profit sector and are seen as an alternative to public sector funding and charitable resource constraints. As SE gains more and more recognition (such as legitimacy), social entrepreneurs increasingly feel that they lack sufficient resources. The ability to acquire and maintain resources is a key factor in seeking legitimacy. They believed that the five factors of organizational legality pressure, homogenization pressure, political pressure, structural pressure and moral pressure are described as the power to restrain social entrepreneurs from effectively solving a wide range of social problems. According to Miller and Wesley, SE essentially includes the unique qualities of both the social and entrepreneurial sectors, but the main goals and resources of the two sectors are often different (Sud et al, 2009). These SE organizations often need to maintain a diverse nature to maintain the legitimacy of their many stakeholders. The mission of social enterprises is linked to moral legitimacy, and moral legitimacy is the justification for supporting SE. The second is to analyze the external legitimacy of SE from the perspective of micro-rhyme strategies based on social entrepreneurs, builders of social network relationships, governments and other stakeholders For example, Nicholls(2010) used the new institutional theory approach to focus on the micro-structure of SE legalization, from the perspective of the main actors of SE, discourse and emerging narrative logic to explain the development of SE. Studies have shown that the dominant discourses of SE represent the legitimacy of resource-rich actors in the process of reflexive isomorphism. Ruebottom (2013) believed that gaining legitimacy can be a challenge for social entrepreneurs seeking to change existing community practices. Through a case study of 10 social 
enterprises, it was found that rhetorical strategies can help overcome this obstacle. These rhetorical strategies can combine protagonists and opponents to create tensions and persuade the public to accept the legitimacy of social enterprises. Their micro-structures include meta-narratives that refer to social acceptance and emphasis on positive protagonist narratives. And the rhetorical means of the negative opponent's meta-narratives.

\subsection{Research on the factors affecting SE and performance evaluation}

Like commercial entrepreneurship, the success of SE is also affected by multiple factors. Austin et al.,(2006) believed that similar to commercial entrepreneurship, there are quite a number of factors in the external environment, such as macroeconomics, taxation and regulation, and social and political environment, which have an impact on SE. Weerawardena and Mort(2006) have two main constraints on SE. The first is static constraints, which is the driving force for organizational sustainability and social mission. The second is dynamic constraints, that is, turbulence. The impact of the environment. The potential impact of dynamic environmental constraints on maximizing social value is environmental change and challenges, such as changing social needs, government policies, or competition from for-profit companies. Estrin et al.,(2016) analyzed the commonalities and differences between SE and commercial entrepreneurship by establishing a multi-level framework, arguing that specific entrepreneurial human capital is relatively important in business entrepreneurship, while general human capital is SE. More important, the role of human capital depends on the rule of law. Compared with business entry, SE projects have a comparative advantage in a weak institutional environment. Where the rule of law is weak, commercial projects may be at risk, but SE projects are less risky. In addition, social enterprises are more likely to be founded by highly educated people, indicating the need to raise awareness and support for SE among students. Sharir and Lerner (2006) conducted a case study of 33 social enterprises established in Israel since 1990, and tested 8 of the 15 variables from the four dimensions of entrepreneurs, environment, organization and process to contribute to the success of SE. Parkinson and Howorth (2008) drew on phenomenological research and discourse analysis to analyze the micro-discourse of social entrepreneurs, rather than the meta-revolution of social entrepreneurs. In the rhetoric of social entrepreneurs, the language of business and entrepreneurship is considered to be the way forward for social enterprises.

Since SE has both economic value and social value, there is a significant difference between the SE performance evaluation model and the business entrepreneur performance evaluation. It is necessary to measure the social enterprise performance from different perspectives. Austin et al., (2006) believed that business entrepreneurship could rely on relatively tangible and quantifiable performance measures such as financial indicators, market share, customer satisfaction and quality, but social purpose of SE poses a greater challenge to its performance measurement because of the non-quantitative, multiplicity, time factors and perceived differences in the social impacts. After all, the number of financial and non-financial stakeholders involved in social enterprises is more and more varied, which makes managing these relationships more complicated. Grimes et al., (2013), through three cases of internal financial relationships in SE organizations, demonstrates the impact of performance measurement on organizational identity in social sectors. The results showed that SE organizations not only used performance measurement as a means of accountability, but also as a form of accountability. Tools to make SE an organizational identity. Ruvio and Shoham (2011) proposed a multi-level model to explain the performance results of social enterprises. The study examines the relationship between social entrepreneurs' motivations and visions, corporate strategies and environments, the performance of startups, and the survival of newer Israeli companies. The results of the study indicate that the motivations of social entrepreneurs are reflected in their vision, 
which in turn translates into their corporate strategy, further affecting the performance of social enterprises. Stevens et al., (2015) used high-level confirmatory factors to analyze 270 social enterprises, determined the dimensions and measurement methods of social mission and economic mission, and explained how these two constructs are related, providing opportunities for future quantitative research of SE.

\section{Conclusions and Research Prospects}

\subsection{Conclusions}

This paper summarizes the spatial and temporal distribution, hot topics and frontiers of current SE research through the knowledge map tool, which provides a rich literature basis for SE research. The study found the following conclusions: First, SE research is in a period of rapid rise. The United States and Europe have led research in the field of SE. Spain, Canada, Australia and Germany have great academic influence in the field of SE research; Indiana University, Cambridge University, Oxford University, and Queensland University of Technology are the high-yield institutions of SE research literature.The most published literature is Indiana University, the most academically influential is Oxford University; the third is AMR and ETP respectively.The two directions of management and entrepreneurship represent the authoritative research of the world's top management academic journals in the field of SE. A group of scholars represented by Shane, Mair, Austin, Dees, Zahra, etc. have a great influence on the research in the field of SE; The three research hotspots of SE are the connotation and characteristics of SE, SE process, influencing factors and performance evaluation.

\subsection{Research review and prospects}

At present, global SE practice is ahead of the theory. A large number of social enterprises and SE projects have emerged and played an important role in solving social pain problems. At the same time, SE has also entered the mainstream academic research field. The number of documents in the world's top management and entrepreneurial academic journals is rising rapidly. Whether it is research perspective, research content, or research methods, there are still many shortcomings. . In particular, SE research in the context of China has just begun, facing the embarrassment that theoretical research clearly lags behind practical activities. At present, domestic scholars have made some preliminary research on the review of SE literature, but most of these research reviews select some representative research literatures, and lack comprehensive and systematic review of the literature in the field of top management and entrepreneurship in the world. The theme of SE research also has no clear direction.

Based on the analysis of knowledge of SE research and the reality of domestic SE research, we believe that the future SE research trend is worthy of attention in the following three directions:

First of all, from the perspective of research, SE research should gradually shift from "outside" to "inside", that is, from focusing on social enterprises to internal research, based on detailed case studies and analysis, opening up "black boxes" within social enterprises and exploring What resources and capabilities and how to gain competitive advantage within a social enterprise. For example, social enterprise governance model, organizational structure, internal incentive mechanism, human resource management, financial management, SE leadership, corporate culture, etc., the research and exploration of these issues are conducive to the improvement of the internal operating mechanism of social enterprises and increased competitiveness.

Secondly, from the perspective of research methods, SE research should gradually change from 
"narrow" to "wide", that is, one should focus on the interdisciplinary and interdisciplinary research of SE from a single discipline to multidisciplinary integration, from microscopic, In the middle and the macro level, we will discuss the issue of SE in depth; the second is to analyze from a single case to multiple cases, especially the need to consider the strong social embeddedness of SE, and increase the multi-case analysis of social enterprises across the situation, especially the Chinese context. Thirdly, it should jump out of simple descriptive analysis and simple case study, pay more attention to designing and constructing models based on big data sample size, and use quantitative statistical analysis tools to mine data and conduct quantitative analysis to promote the empirical research of SE continue to deepen.

Finally, from the research content, SE research should gradually expand from "shallow" to "deep", that is, based on the current hot topics of SE research in Europe and the United States, and more focus on the unique research of SE and local context-related research. The focus can be studied from the following aspects: (1) What are the characteristics of social entrepreneurs and social entrepreneurial teams that are more conducive to social value creation? (2) Which entrepreneurial processes and strategies are more effective in creating social values in different social entrepreneurial activities? (3) What are the differences between the opportunity discovery and creation process of social entrepreneurs and the opportunity discovery and creation process of general business entrepreneurs? (4) What are the differences between attitudes of social entrepreneurs and general business entrepreneurs in dealing with risks? (5) Compared with general business entrepreneurship, what are the specialities of the means of obtaining resources in the SE process? (6) How does the new technology represented by Internet+ bring competitive advantage to SE? What are the similarities and differences between SE and general business entrepreneurship in the use of new technologies? (7) Does the factor that promotes change in general business entrepreneurship have applicability in SE? (8) What are the differences between the combination of the elements of the social enterprise business model and the elements of the business model of the general commercial enterprise? (9) Is the contractual mechanism of influence investment (or venture philanthropy) in the SE field unique compared with venture capital in the commercial sector? How is the ecosystem of impact investment (or venture philanthropy) built? (10) How to effectively evaluate the social value and social influence investment of social enterprises?

\section{Acknowledgments}

This work was financially supported by China Postdoctoral Science Research Fund Project

"Research on the Mechanism, Path and Model of Rural Revitalization Based on Social Entrepreneurship Theory” (2018M630422)

\section{References}

[1] Johnson. Literature review on social entrepreneurship. Canadian Centre for Social Entrepreneurship Working Paper, 2000.

[2] Dacin M T, Peter A. Dacin, Paul Tracey. Social Entrepreneurship: A Critique and Future Direction [J].Organization Science, 2011, 22(5):1203-1213.

[3] Dees J G.New Definitions of Social Entrepreneurship: Free Eye Exams and Wheelchair Driver. 2003 [DB/OL]. http://www.fuqua.edu/admin/extaff/news/faculty/dees_2003.htm,2003.

[4] Austin J, Stevenson H, Wei-Skillern, J. Social and Commercial Entrepreneurship: Same, Different, or Both?

[J].Entrepreneurship Theory and Practice. January 2006, 30(1):1-22.

[5] Zahra S A, Wright, M, Understanding the Social Role of Entrepreneurship [J]. Journal of Management Studies, 2016, 53(4):610-629.

[6] Hockerts K. Determinants of Social Entrepreneurial Intentions [J].Entrepreneurship Theory and Practice, January 2017, 41(1):105-130. 
[7] Alter S K. Managing the Double Bottom Line: A Business Planning Guide for Social Enterprises. Washington, D.C.: Save The Children, 2000.

[8] Defourny J, Nyssens M. Conceptions of Social Enterprise and Social Entrepreneurship in Europe and the United States: Convergences and Divergences [J]. Journal of Social Entrepreneurship, March 2010, 32-53.

[9] Salamon L M. Leverage for Good: An Introduction to the New Frontiers of Philanthropy and Social Investment. Oxford New York Oxford University Press, 2014.

[10] Goodall A, Oswald A. Do the Social Sciences Need a Shake-up?[N].Times Higher Education, October 9, 2014.

[11] Shane S, Venkataraman S. The Promise of Entrepreneurship as a Field of Research [J].Academy of Management Review, January 2000,25(1), 217-226.

[12] Mair J, Marti I. Social Entrepreneurship Research: A Source of Explanation, Prediction, and Delight [J].Journal of World Business, February 2006, 41(1):36-44.

[13] Peredo AM, McLean M. Social entrepreneurship: A critical review of the concept [J].Journal of World Business, February 2006, 41(1):56-65.

[14] Weerawardena J, Mort GS. Investigating Social Entrepreneurship: A Multidimensional Model [J].

Journal of World Business, 2006, 41(1): 21-35.

[15] Short JC, Moss TW, Lumpkin, GT. Research in Social Entrepreneurship: Past Contributions and Future Opportunities [J].Strategic Entrepreneurship Journal, 2009, 3 (2):161-194.

[16] Tracey P, Phillips N, Jarvis O. Bridging Institutional Entrepreneurship and the Creation of New Organizational Forms: A Multilevel Model [J].Organization Science, 2011, 22(1):60-80.

[17] Mair J, Battilana J, Cardenas J. Organizing for Society: A Typology of Social Entrepreneuring Models [J].Journal of Business Ethics, December 2012, 111(3):353-373.

[18] Stevens R, Moray N, Bruneel J. The Social and Economic Mission of Social Enterprises: Dimensions, Measurement, Validation, and Relation [J].Entrepreneurship Theory and Practice, September 2015, 39(5):1051-1082.

[19] Mcmullen JS, Bergman Jr BJ.Social Entrepreneurship and the Development Paradox of Prosocial Motivation: A Cautionary Tale [J]. Strategic Entrepreneurship Journal, September 2017, 11(3): 243-270.

[20] Zahra SA, Gedajlovic E, Neubaum DO.A Typology of Social Entrepreneurs: Motives, Search Processes and Ethical Challenges [J].Journal of Business Venturing, September 2009, 24(5): 519-532.

[21] Renko M. Early Challenges of Nascent Social Entrepreneurs. Entrepreneurship Theory and Practice [J]. September 2013, 37(5):1045-1069.

[22] Parkinson C, Howorth C. The language of social entrepreneurs[J].Entrepreneurship and Regional Development, April 2008,20(3),285-309.

[23] Vaness R, Isabell MW. Special Issue: Community-based, Social and Societal Entrepreneurship [J]. Entrepreneurship and Regional Development, June 2011, 23(5-6):283-286.

[24] Katre A, Salipante P. Start-Up Social Ventures: Blending Fine-Grained Behaviors from Two Institutions for Entrepreneurial Success [J].Entrepreneurship Theory and Practice, September 2012, 36(5):967-994.

[25] Lumpkin G T, Moss TW, David M, et al. Entrepreneurial Processes in Social Contexts: How Are They Different, If At All? [J].Small Business Economics. April 2013,40(3):761-783.

[26] Patricia DC, Marcus HH. How Opportunities Develop in Social Entrepreneurship [J]. Entrepreneurship Theory and Practice, July 2010,34(4):635-659.

[27] Zahra SA, Rawhouser HN, Bhawe N, et al. Globalization of Social Entrepreneurship Opportunities [J]. Strategic Entrepreneurship Journal, June 2008, 2(2):117-131.

[28] Grimes MG, McMullen JS, Vogus TJ, et al. Studying the Origins of Social Entrepreneurship: Compassion and the Role of Embedded Agency [J].Academy of Management Review, 2013, 38(3), 460-463.

[29] Domenico M, Haugh H, Tracey P. Social Bricolage: Theorizing Social Value Creation in Social Enterprises [J]. Entrepreneurship Theory \& Practice, July 2010, 34(4), 681-703.

[30] Meyskens M, Carsrud AL, Cardozo RN. The Symbiosis of Entities in the Social Engagement Network: The Role of Social Ventures [J].Entrepreneurship and Regional Development. 2010, 22(5): 425-455.

[31] Desa G. Resource Mobilization in International Social Entrepreneurship: Bricolage as a Mechanism of Institutional Transformation [J].Entrepreneurship Theory and Practice, 2012, 36(4): 727-751.

[32] Desa G, Basu S. Optimization of Bricolage? Overcoming Resource Constraints in Global Social Entrepreneurship [J].Strategic Entrepreneurship Journal, March 2013, 7(1):26-49.

[33] Miller TL, Mattew G, McMullen JS,et al. Venturing for Others with Heart and Head: How Compassion Encourages Social Entrepreneurship[J]. Academy of Management Review. October 2012, 37(4):616-640.

[34] Sud M, VanSandt CV, Baugous AM. Social Entrepreneurship: The Role of Intitutions[J]. Journal of Business Ethics, February 2009, 85(1):201-216.

[35] Nicholls A.The Legitimacy of Social Entrepreneurship: Reflexive Isomorphism in a Pre-Paradigmatic Field [J].Entrepreneurship Theory and Practice, July 2010, 34(4):611-633. 
[36] Ruebottom T. The Microstructures of Rhetorical Strategy in Social Entrepreneurship: Building Legitimacy through Heroes and Villains [J].Journal of Business Venturing, January 2013, 28(1):98-116.

[37] Estrin S, Mickiewicz T, Stephan U. Human capital in social and commercial entrepreneurship [J]. Journal of Business Venturing, July 2016, 31(4):449-467.

[38] Sharir M, Lerner M. Gauging the Success of Social Ventures Initiated by Individual Social Entrepreneurs [J]. Journal of World Business, February 2006, 41(1):6-20.

[39] Ruvio AA, Shoham A.A Multilevel Study of Nascent Social Ventures[J].International Small Business Journal[J],October 2011,29(5):562-579.

[40] Stevens R, Moray N, Bruneelet J. The Social and Economic Mission of Social Enterprises: Dimensions, Measurement, Validation, and Relation [J]. Entrepreneurship Theory and Practice, September 2015, 39(5):1051-1082. 